\title{
The Future of Maternal and Child Health
}

\author{
Michael C. Lu ${ }^{1}$
}

Published online: 19 November 2018

(c) Springer Science+Business Media, LLC, part of Springer Nature 2018

\begin{abstract}
Introduction The purpose of this commentary is to start a national conversation about the future of maternal and child health $(\mathrm{MCH})$. In the coming decades, we will have unprecedented opportunities to improve $\mathrm{MCH}$, but will also face unprecedented threats.

Methods This paper examines emerging opportunities and threats to $\mathrm{MCH}$, and discusses strategies for leading the future of $\mathrm{MCH}$.

Results Scientific advancements will continue to drive improvements in $\mathrm{MCH}$, but to unleash its full potential for improving population health future $\mathrm{MCH}$ research must become more transdisciplinary, translational, and precise. Technological innovations could dramatically transform our work in $\mathrm{MCH}$ while big data could enhance predictive analytics and precision health; our challenge will be to assure equitable access. The greatest gains in $\mathrm{MCH}$ will continue to come from improving social conditions, which will require advancing $\mathrm{MCH}$ in all policies. Climate change, infectious outbreaks and antimicrobial resistance pose increasing threats to $\mathrm{MCH}$, which can be averted by reducing global warming, implementing global early warning systems, and instituting responsible antimicrobial stewardship. The growing burden of chronic diseases in children and adults need to be addressed from an ecological and life course perspective. The water crisis in Flint shined a spotlight on the growing health threats from America's decaying infrastructure.

Discussion We can lead the future of $\mathrm{MCH}$ by starting a national conversation, improving $\mathrm{MCH}$ research, and preparing future $\mathrm{MCH}$ workforce, but the future of $\mathrm{MCH}$ will depend on our effectiveness in bringing about social and political change in the coming decades.
\end{abstract}

Keywords Future of maternal and child health $\cdot$ Life course $\cdot$ Technology $\cdot$ Innovation $\cdot$ Precision $\cdot$ Health $\cdot$ Big data . Climate change $\cdot$ Infectious outbreaks $\cdot$ Antimicrobial resistance $\cdot$ Chronic diseases $\cdot$ Infrastructure $\cdot$ Social inequality $\cdot$ Research $\cdot$ Workforce $\cdot$ Health in $\cdot$ All policies

\section{Significance}

This purpose of this commentary is to start a national conversation about the future of maternal and child health $(\mathrm{MCH})$. It discusses emerging opportunities and threats to $\mathrm{MCH}$, and discusses strategies for leading the future of $\mathrm{MCH}$.

Michael C. Lu

mclu@gwu.edu

1 Department of Prevention and Community Health, Milken Institute School of Public Health, George Washington University, 950 New Hampshire Avenue NW Suite 219, 20052 Washington, DC, USA

\section{Introduction}

Maternal and child health is what we do together as a society to ensure the conditions in which all women, children, and families can be healthy. While our mission has remained constant for over a century, what we do has changed over time in response to new opportunities and threats. Reports of poor health among World War I recruits and the passage of the nineteenth amendment led to the Sheppard-Towner Act in 1921 (Brosco 2012). The development of polio vaccine in 1954 and phenylalanine assay in 1962 gave rise to large scale children's immunization and newborn screening programs (Brosco 2012). In every decade, scientific discoveries, medical breakthroughs, changing epidemiological patterns, political and economic forces, and other societal trends have shaped and reshaped our work in $\mathrm{MCH}$. 
What does the future hold for $\mathrm{MCH}$ ? There are megatrends and megaforces on the horizon that could dramatically transform how we work in $\mathrm{MCH}$. In the coming decade, we will have unprecedented opportunities to improve the lives of women, children, and families. At the same time, we will also face unprecedented threats to the health of our populations. Are we ready for our future?

The purpose of this paper is to start a national conversation about the future of MCH. I believe it is important to start this conversation now for several reasons. First, we need to prepare our future workforce for where $\mathrm{MCH}$ is going to be, and not just where it is or has been. Second, we can take actions now to capitalize on emerging opportunities and avert future threats. Third, we can work to shape our future in keeping with our mission, vision and values. In this paper, I will examine major opportunities and threats in the coming decade, and discuss what we must do, as leaders of $\mathrm{MCH}$, to lead the future of $\mathrm{MCH}$.

\section{Scientific Advancements}

I will start with opportunities on the horizon to improve $\mathrm{MCH}$. Scientific advancements over the past decades have dramatically transformed our field. Major advances in neurobiology, genomics and epigenetics, developmental origins of health and disease, and life course health sciences have provided new insights into how health and disease develop over the life course (Halfon et al. 2014). This, in turn, has redefined our work from simply gap-filling or wrap-around for health care, or even health promotion and disease prevention in $\mathrm{MCH}$, to health production and optimization across the life course. $\mathrm{MCH}$ is in the business of producing population health for the future.

In the next decade, scientific advancements will undoubtedly continue to drive improvements in $\mathrm{MCH}$, but to truly shift the curve on population health, scientific discoveries will need to be more rapidly translated into effective clinical and public health strategies (Lu 2014). As discussed later, this may require a more transdisciplinary approach than what currently prevails in $\mathrm{MCH}$ research, and a nimbler research and development (R\&D) platform than what present-day randomized controlled trials can support (Center on the Developing Child at Harvard University 2016). But the greatest limit on the potential population-wide impact of scientific advancements will be the market forces that are driving their development and distribution, which could leave behind large segments of $\mathrm{MCH}$ populations who could not access or afford them. Thus, an important $\mathrm{MCH}$ leadership challenge (and a recurrent theme of this commentary) is how to assure equitable access to science, technology and data that could change lives and improve health for all children and families.

\section{Technological Innovations}

Another major opportunity for improving $\mathrm{MCH}$ in the next decade will come from technological innovations. Already several innovations on the horizon are showing promise for improving health, such as the use of CRISPR for treatment of genetic disorders; the use of robotic limbs to transform disability into super-ability; and the use of biosensors for non-invasive glucose monitoring in children with Type-I diabetes mellitus.

These technological innovations could also dramatically transform our work in $\mathrm{MCH}$. Take prenatal care, as an example. Much of prenatal care today is still centered around the office visit, and despite the lack of evidence for the schedule of visits current guidelines continue to recommend 14 or more prenatal visits during pregnancy. For many women but especially low-income women, this often requires taking unpaid leave from work, arranging childcare and transportation, waiting an hour or two for a 5- to 10-minute visit, which consists largely of a spot blood pressure check and urine dip, a cursory auscultation of fetal heart tone and fundal height measurement, and a hurried conversation with a provider who, despite the best of intentions, often do not have sufficient time or training to educate patients about self-care let alone addressing their psychosocial concerns or occupational and environmental exposures. Is this the best we can do for our nation's mothers and babies?

How can technology help bring prenatal care into the twenty-first century? In the next decade, new technologies such as wearables, sensors, and lab-on-a-chip could be developed to collect high quality data on a more continuous basis from the comfort of the woman's own home (Haghi et al. 2017). Such data may include not only information on blood pressure or urine protein, but also nutrition and physical activities, stress and sleep, occupational, environmental, and other exposures that truly matter to pregnancy outcomes and developmental origins of health and disease. These data could be transmitted on an ongoing basis to a cloud which, with the aid of artificial intelligence (AI) and machine learning, could help triage women to routine follow-up, a call from a health educator, a visit from a home visitor, or an appointment with a specialist. For women living in under-resourced or remote areas, telehealth could vastly expand access while eHealth can enhance health promotion. These technological innovations, along with design and systems thinking, can help us redesign prenatal care around the needs of the woman and her family, and not simply the convenience of the provider or the bottom line of the health care enterprise.

While technology holds big promise for improving $\mathrm{MCH}$, it has its limits. First, technology cannot replace 
human touch, especially in $\mathrm{MCH}$. But when properly used, high tech can enhance high touch; for example, AI and machine learning can assist with care coordination and enhance family engagement. Second, technological innovations do not automatically advance health equity. In fact, technology can widen health disparities if there is differential access. Thus, as efficacy of technology for improving health outcomes grows, so will our burden in assuring equitable access to technology for all those in need (Wise 2012). Third, high tech may come with high opportunity costs. In pursuit of technological innovations to improve individual lives in $\mathrm{MCH}$, we must not lose sight of what truly matters to population health in $\mathrm{MCH}$, including many social determinants of health which will require political and policy solutions and not technological fixes.

\section{Big Data}

The era of big data will also usher in new opportunities for improving $\mathrm{MCH}$. Big data refers to volumes of large, complex information, often from unrelated sources, that can be linked (Khoury and Ioannidis 2014). In clinical medicine, linking genomic and other -omic data with clinical and administrative data has enabled clinicians to better predict and prevent diseases and personalize treatment to more precisely address individual risks - the right drug for the right patient under the right conditions. In public health, linking these data with social, environmental, geospatial, and even climate data can improve public health surveillance and intervention. In the Juniper Pollens Project (National Aeronautics and Space Administration 2018), researchers linked data from satellite images, weather forecast, and local pollen samples to improve prediction and early warning to people with allergies and asthma of the timing and pattern of pollen release and spread. Such transdisciplinary collaboration among NASA scientists, weather researchers, and local volunteers, aided by big data from unrelated sources, exemplifies how our work in $\mathrm{MCH}$ could be evolving.

Big data holds big promise for the future of $\mathrm{MCH}$. In research, linking data from multiple sources and across multiple domains, from cells to society, neurons to neighborhoods, and preconception to old age, could offer greater insights into how health and disease develop over the life course, and why some people are healthier and others are sick. In practice, linking data from all the wearables and biosensors as well as other biological, clinical, social, and environmental data, crowdsourced in the cloud from millions of anonymized end-users, could help us develop better predictive analytic models to identify which women are at risk for pregnancy complications, and which children are at risk for developmental delays, and thus could benefit from early interventions. Like precision medicine, linking all these data could also help us more precisely tailor interventions to address specific risks of individuals, families, or communities, and move the field beyond one-size-fits-all solutions toward precision $\mathrm{MCH}$, targeting the right intervention for the right patient or population under the right circumstances.

However, big data also come with big perils. First, big data can cause big errors with spurious correlations and ecological fallacies; thus big data will always need to be grounded in a strong foundation of fundamentally sound MCH epidemiology (Khoury and Ioannidis 2014). Second, big data can cause big problems with privacy; every effort should be made to protect data privacy. Third, as with technology, big data can widen disparities if there is differential access. Data quality and quantity are often limited for underserved and marginalized populations; thus an important leadership challenge in the future will be how to put big data to work for health equity, and not widen health disparities.

\section{Societal Improvements}

While science, technology and big data will undoubtedly advance $\mathrm{MCH}$ in the coming decade, the biggest gains will still come from improving social conditions for all women, children and families. We should not forget that some of the greatest improvements in $\mathrm{MCH}$ over the past 150 years were achieved with better sanitation and hygiene, cleaner water and a safer food supply, enactment of child labor laws and women's suffrage, and overall improvements in educational attainment, economic opportunities, and social status of women and children in our nation and around the world (Brosco 2012).

Improving social conditions requires us to work outside of our comfort zone in $\mathrm{MCH}$, building collaborations across multiple sectors including education, housing, social services, economic and community development to address social determinants. But the expectation that collaboration will occur spontaneously is the reason why most collaborations fail (Kania and Kramer 2011). Successful collaboration requires a common agenda, shared measurement, coordinated and mutually reinforcing strategies, continuous communication, and backbone organization to achieve the greatest collective impact (Kania and Kramer 2011). Increasingly public health departments will be called upon to play the role of a backbone organization to improve health outcomes in a community.

Improving social conditions will also require us to work upstream to fight policies that are harmful to $\mathrm{MCH}$, such as policies that restrict access to comprehensive reproductive health services; or tax, welfare and child support policies that disengage father involvement (Lu et al. 2010); or de facto redlining and disinvestment in our inner cities that are 
creating hypersegregation and hyperconcentration of poverty in some communities of color; or economic and tax policies that are driving growing social inequality; or the deregulation of environmental protection which will disinherit our children of their future. Protecting the future of $\mathrm{MCH}$ requires us to fight for $\mathrm{MCH}$ in all policies.

\section{Climate Change}

Climate change has been identified by the World Health Organization as one of the greatest threats to public health in the twenty-first century (World Health Organization 2018), and it could certainly have devastating impact on $\mathrm{MCH}$. From weather-related disasters such as hurricanes, wildfires, and flooding of our coastal cities and islands which could displace millions of women, children, and families in years to come; to the spread of vector-born diseases such as Zika, with tropical vectors like Aedes aegypti spreading as far north as Maine and Washington because of climate change (Centers for Disease Control and Prevention 2017); to severe droughts which could devastate food production and worsen air quality; climate change is one of the biggest threats to $\mathrm{MCH}$ that merits greater attention from our field.

What can $\mathrm{MCH}$ do about climate change? First, $\mathrm{MCH}$ researchers and funders need to prioritize climate change research in the next decade. Second, $\mathrm{MCH}$ advocates need to join forces with climate and other advocates to advance policies and practices that promote clean, renewable energy, cut carbon dioxide emission, support climate-friendly refrigeration solutions, and reduce global warming. Also, every state Title V program needs to work with its state emergency management office to put a statewide emergency preparedness plan and system in place for MCH. The U.S. Department of Health and Human Services needs to revise its Emergency Support Function \#8 (ESF-8) to allow states to access Federal Emergency Management Agency (FEMA) funds to address the immediate needs of pregnant women, infants and children with special health care needs, without having to wait for Congressional appropriations for disaster relief which often get stalled for political reasons (Federal Emergency Management Agency 2018). MCH cannot afford to sit on the sideline on climate change.

\section{Infectious Outbreaks \& Antimicrobial Resistance}

Another major threat to $\mathrm{MCH}$ in the coming decade is infectious outbreaks. Already in the first 2 decades of this century, we've seen major outbreaks including Avian Flu, severe acute respiratory syndrome (SARS), H1N1 Flu, Middle East Respiratory Syndrome (MERS), Ebola, Zika, and others.
These outbreaks have been driven by climate change, urbanization, and globalization, trends which are likely to continue over the next decade.

The emergence of antimicrobial resistance is another growing threat to $\mathrm{MCH}$. The $\mathrm{CDC}$ estimates that each year in the U.S., 2 million people become infected with, and 23,000 people die from, bacteria that are resistant to antibiotics (Centers for Disease Control and Prevention 2018b). A recent study of 48 children's hospitals found an eightfold increase in the rate of multidrug resistant $E$ coli infections between 2007 and 2015 (Meropol et al. 2007). Antimicrobial resistance is driven largely by inappropriate antibiotic prescription; it has been estimated that at least $30 \%$ of all antibiotics prescribed in the U.S. are unnecessary. Inappropriate administration of antibiotics to livestock, which accounts for $80 \%$ of antibiotic use in the U.S., also contributes to growing resistance (Centers for Disease Control and Prevention 2018b).

What can we do about infectious outbreaks and antimicrobial resistance? First, $\mathrm{MCH}$ can play an important role in coordinating between public health and clinical medicine to implement in every community and every state responsible antimicrobial stewardship in MCH (Centers for Disease Control and Prevention 2018b). Second, MCH needs to join forces with the One Health movement, which recognizes that the health of people is interconnected with the health of animals and the environment (Centers for Disease Control and Prevention 2018a). Third, using microbial whole genome sequencing and social network analysis to monitor chatters and tweets, we have the know-how to put in place a global early warning system for early detection and rapid response to an infectious outbreak or the emergence of antimicrobial resistance (Gardy et al. 2011). The question remains whether we have the political will to get it done.

\section{Growing Burden of Chronic Diseases}

Another major threat is the growing burden of chronic diseases. According to the 2016 National Survey of Children's Health, approximately $38 \%$ of American children have a chronic health condition, and $20 \%$ have a special health care need (Child and Adolescent Health Measurement Initiative 2016). The 2013 National Health Interview Survey found 6 to $8 \%$ of children have a severe disability that limits their activities of daily living (Halfon et al. 2012). Nearly a third (31\%) of American children are now overweight or obese (Child and Adolescent Health Measurement Initiative 2016), a rate that has more than tripled since the 1970s. Anxiety and depression also appear to be increasing among children and adolescents in this country, with $30 \%$ of high school students reporting depressive symptoms in the past 12 months 
(U.S. Department of Health and Human Services. Office of Adolescent Health 2018).

But the growing burden of chronic diseases among children and youth pales in comparison to that among adults, with $80 \%$ of adults over 65 having at least one chronic condition; and more than two-thirds having 2 or more chronic conditions (National Council on Aging 2018). More than 1 in 4 have diabetes, and more than 1 in 10 have Alzheimer's disease. With more than 50 million adults 65 and older in the U.S. today, which is projected to grow to 70 million in the next decade (National Council on Aging 2018), the growing burden of chronic diseases among our aging population is going to put increasing strain on our health care system and political will, potentially undermining support for investments in $\mathrm{MCH}$.

What can MCH do? First, we must intervene earlier than we have been. For example, a growing body of evidence in life course health sciences suggests that current $\mathrm{MCH}$ interventions may be doing too little too late; that if we want to prevent child obesity and adult metabolic syndrome, our interventions need to begin before birth or better yet, before conception (Huang et al. 2007). Second, we must address the social ecology of chronic diseases, for examples, food deserts for obesity; substandard housing for asthma; adverse childhood experiences and neighborhood violence for some kids, and social media and achievement pressures for other kids that are fueling the rise in anxiety and depression among our youth. Third we need more research on the growing burden of chronic diseases among our nation's children and adults, not only to better understand the problems and root causes, but also to develop better clinical and population-based prevention and interventions strategies to turn the tide on chronic diseases.

\section{Decaying Infrastructure}

Whereas clean water and sanitation played a key role in improving $\mathrm{MCH}$ in the last century, decaying infrastructure, including our Nation's drinking water and waste management systems which received grades of D and D+, respectively, on the 2017 Infrastructure Report Card from the American Society of Civil Engineers (American Society of Civil Engineers 2018), will increasingly threaten MCH in the coming decades. While Flint, Michigan put a momentary spotlight on the problem, there are many more affected communities besides Flint, including more than 1300 Superfund sites across the country, and many more neurotoxicants besides lead to which millions of children and families are exposed daily, that still need to be cleaned up.

What can MCH do? First, MCH needs to join forces with other advocates in advancing an infrastructure bill that will fix our nation's drinking water and waste management systems, and build walkable sidewalks and bike paths, public parks and public transits, and not just privatized toll roads. Second, we need to support legislation and regulations to strengthen toxicity testing, premarket evaluation, and ongoing epidemiological monitoring of environmental chemicals (Landrigan and Goldman 2011). Third, we can activate citizen science for environmental monitoring. By mobilizing an army of ordinary citizens armed with low-cost testing kits and basic training for monitoring air and water pollution (McKinley et al. 2017), we don't have to wait for the EPA to act; we can crowdsource environmental protection for our children's future.

\section{Leading the Future of $\mathrm{MCH}$}

In the face of these emerging opportunities and threats, what must we do, as leaders of $\mathrm{MCH}$, to lead the future of $\mathrm{MCH}$ ? Instead of waiting for the vortex of all these megatrends and megaforces, opportunities and threats to swallow us up, we can work to shape our future in keeping with our mission, vision and values. That is our leadership responsibility, to lead our field into the future we want-a future driven by mission and values rather than political or market forces; a future powered by science and evidence and not politics or ideology; a future where data and technology close rather than widen gaps; a future that puts children first and families front and center; and a future where every child and family have a fair shot at reaching their fullest potential.

Getting there will require leadership. First and foremost, it will require generating the necessary political will in our nation to take on issues that truly matter to $\mathrm{MCH}$. As much as we'd like to think that we can fix all $\mathrm{MCH}$ problems with $\mathrm{MCH}$ programs and services, tackling the root causes of some of our biggest problems will require social and political change. For too long MCH has toiled downstream to ameliorate the harms caused by decisions made upstream. We cannot reverse climate change by doing more disaster preparedness plans, nor can we screen and intervene our way to health equity without addressing poverty, racism, and the social injustices that give rise to health disparities.

The future of MCH will depend on our effectiveness in bringing about real social and political change in the coming decades. This will require mobilizing grassroots movements, building broad coalitions, joining forces and generating sufficient political will to take actions, against vested corporate and political interests, to reverse global warming, clean up toxic waste sites, rebuild our nation's infrastructure, address social determinants, reduce social inequality and assure the social conditions in which all children and families can be healthy and thriving. It will also require building a clear policy platform and political strategy for $\mathrm{MCH}$, and over the next decade electing political candidates at the local, state, 
and federal levels who will carry the platform and advance the agenda.

Most importantly, it will require us to put $\mathrm{MCH}$ leaders in positions of power where they can have a voice on issues that truly matter to $\mathrm{MCH}$. We should not forget that Martha May Eliot did not just stop at preventing rickets or running the Bureau; she drafted much of the language for Title $\mathrm{V}$ of the Social Security Act which has shaped the future of $\mathrm{MCH}$ for the next eighty years and beyond (Brosco 2012). We need to grow a new generation of MCH leaders like Martha May Eliot to rise up into positions of power in the coming decade. From the White House to every state house, from the hallways of Congress to every city hall, from corporate boardrooms to every federal courtroom, $\mathrm{MCH}$ leaders need to infiltrate every decision-making body where key policy decisions are being made that could impact the health and lives of our Nation's children and families. That is how we will lead the future of $\mathrm{MCH}$, by fighting for $\mathrm{MCH}$ in all policies.

A second way by which we can lead the future of $\mathrm{MCH}$ is by accelerating finding solutions to $\mathrm{MCH}$ problems, which may necessitate transforming how we do and fund future research in $\mathrm{MCH}$ (Lu 2014). First, our research must become more transdisciplinary. Much of current $\mathrm{MCH}$ research still takes place in siloes-institutional siloes, disciplinary siloes, disease siloes, ages and stages siloes. To accelerate scientific breakthroughs, future $\mathrm{MCH}$ research needs to take a more integrative approach that engages collaboration across basic, clinical, social, behavioral and data sciences, systems and population health sciences, and most importantly, families and communities, recognizing that cognitive diversity and transdisciplinarity are our field's greatest strengths as well as major drivers of future innovations (Lu 2014; National Research Council 2001).

Second, our research must become more translational. Much of current MCH research is still stuck in describing, explaining, and admiring problems rather than doing something about them. For example, despite a growing body of observational studies suggesting the critical role that early nutrition plays in developmental origins of health and disease, few intervention studies have been designed with sufficient follow-up to evaluate the impact of early nutritional interventions on child or adult health outcomes. This leaves an open question as to how best to prevent child obesity, early-onset type II diabetes or adult chronic diseases with early nutrition intervention programs (Lu 2014). While discovery research has its place, our field cannot get stuck in the discovery phase. We need a new generation of well-designed translational studies, from bench to bedside and from bedside to curbside, with an effective feedback loop between evidence-based practice and practice-informed research, to accelerate the translation of research into practice and policy (Lu 2014).
Third, our research must become more precise. Much of current $\mathrm{MCH}$ research continues to search (in vain) for one-size-fits-all solutions. The gold standard for research design in our field is still randomized controlled trials (RCTs), which test interventions standardized for the entire study population without being able to account for differential susceptibilities of individuals, families, or communities, and cannot easily be adjusted, adapted, or enhanced after randomization. The effectiveness of many such interventions in our field, including some well-known trials on preschools and home visiting, was evaluated by examining their effect size averaged across the study population compared to that in a control group, often without assessing for whom was the intervention effective, and for whom did the intervention not work at all (Center on the Developing Child at Harvard University 2016). Future $\mathrm{MCH}$ research needs to define more precisely which intervention works best for which patients or populations under what circumstances. While RCTs have their place, such level of precision may require a nimbler research platform that allows for testing of interventions specifically tailored for individual or population risks, and can be adjusted, adapted or enhanced in rapid-cycle micro-trials without losing analytic rigor (Center on the Developing Child at Harvard University 2016). Finding new ways to promote transdisciplinarity, accelerate translation, and improve precision is how we can lead the future of $\mathrm{MCH}$, by unleashing the full potential of future $\mathrm{MCH}$ research to truly improve population health.

A third way by which we can lead the future of $\mathrm{MCH}$ is by preparing our workforce for that future. Advances in science, technology, and big data may displace some jobs while creating new ones; $\mathrm{MCH}$ training and continuing education programs must keep pace with these changing workforce needs. Schools and programs of public health must prepare our future workforce for where $\mathrm{MCH}$ is going to be, and not just where it is or has been. Designing better $\mathrm{MCH}$ systems of the future requires a workforce equipped with design thinking and systems thinking, while keeping up with rapidly growing $\mathrm{MCH}$ sciences and a rapidly changing world requires a workforce skilled in critical thinking and lifelong learning (Petersen and Weist 2014). The role of a "chief health strategist," as envisioned by Public Health 3.0 (DeSalvo et al. 2016), requires development of competencies in change leadership and management, strategic planning and resource management, improvement and innovation, collaboration and communication, and policy and advocacy. The growth of undergraduate public health education could represent an untapped opportunity to prepare a broader future workforce with strong foundation in $\mathrm{MCH}$, while on-line platforms could support ongoing upgrade of knowledge, skills, and tools for the existing MCH workforce (increasingly without foundational $\mathrm{MCH}$ training), 
especially in parts of the nation or globe with limited access to such resources.

Lastly, leading the future of $\mathrm{MCH}$ requires us to start a national conversation about the future we want. It requires developing a clear vision of where we want to go as a field, and how to get there from here. It requires not only reexamining the organization, delivery and financing of $\mathrm{MCH}$ clinical and public health services and systems, but also developing a clear policy agenda and political strategy, and a common vision for what a "Moonshot for MCH" might look like for the next Administration. Most importantly, it requires us to continue to listen to families, give voice to the voiceless, and keep fighting to give every child and family a fair shot at reaching their fullest potential. That is how we lead the future of $\mathrm{MCH}$, by staying true to what $\mathrm{MCH}$ has always been about.

\section{References}

American Society of Civil Engineers. 2017 Infrastructure report card. Retrieved April 7, 2018 from https://www.infrastructurereport card.org/.

Brosco, J. P. (2012). Navigating the future through the past: The enduring historical legacy of federal children's health programs in the United States. American Journal of Public Health, 102(10), $1848-1857$.

Center on the Developing Child at Harvard University (2016). From best practices to breakthrough impacts: A science-based approach to building a more promising future for young children and families. Retrieved April 7, 2018 from http://www.developingchild .harvard.edu.

Centers for Disease Control and Prevention. (2017). Estimated potential range of Aedes aegypti and Aedes albopictus in the United States, 2017. Retrieved April 7, 2018 from https://www.cdc.gov/ zika/vector/range.html.

Centers for Disease Control and Prevention. (2018a). One health. Retrieved April 7, 2018 from http://www.cdc.gov/onehealth/ index.html.

Centers for Disease Control and Prevention. (2018b). About antimicrobial resistance. Retrieved April 7, 2018 from https://www.cdc. gov/drugresistance/about.html.

Child and Adolescent Health Measurement Initiative. (2018). Data Resource Center for Child and Adolescent Health. 2016 National Survey of Children's Health (NSCH) data query. Retrieved April 7, 2018 from http://www.childhealthdata.org. CAHMI: http:// www.cahmi.org.

DeSalvo KB, O'Carroll PW, Koo D, Auerbach JM, Monroe JA. Public health 3.0: Time for an upgrade. American Journal of Public Health. 2016;106:621.

Federal Emergency Management Agency. (2018). Emergency Support Function \#8 - Public Health and Medical Services Annex. Retrieved April 7, 2018 from https://www.fema.gov/media-libra ry-data/1470149644671-642ccad05d19449d2d13b1b0952328ed/ ESF_8_Public_Health_Medical_20160705_508.pdf.

Gardy, J. L., Johnston, J. C., Ho Sui, S. J., Cook, V. J., Shah, L., Brodkin, E., et al. (2011). Whole-genome sequencing and social-network analysis of a tuberculosis outbreak. New England Journal of Medicine, 364, 730-739.

Haghi, M., Thurow, K., \& Stoll, R. (2017). Wearable devices in medical internet of things: Scientific research and commercially available devices. Healthcare Informatics Research., 23, 4-15.

Halfon, N., Houtrow, A., Larson, K., \& Newacheck, P. W. (2012). The changing landscape of disability in childhood. Future of Children, $22,13-42$.

Halfon, N., Larson, K., Lu, M. C., Tullis, E., \& Russ, S. Lifecourse health development: Past, present, and future. Maternal and Child Health Journal 2014;18:344-65.

Huang, J. S., Lee, T. A.. Lu, M. C. Prenatal programming of childhood overweight and obesity. Maternal and Child Health Journal 2007; 11:461 - 73 .

Kania, J., \& Kramer, M. Collective impact. Stanford Social Innovation Review. 2011:36-41.

Khoury, M. J., \& Ioannidis, J. P. (2014). Big data meets public health. Science., 346, 1054-1055.

Landrigan, P. J., \& Goldman, L. R. Children's vulnerability to toxic chemicals: a challenge and opportunity to strengthen health and environmental policy.Health Affairs. 2011;30:842-850.

Lu, M. C. Improving maternal and child health across the life course: Where Do We Go from Here? Maternal and Child Health Journal. 2014;18:339-343.

Lu, M. C., Jones, L., Bond, M. J., Wright, K., Pumpuang, M., Maidenberg, M., Jones, D., Garfield, C., \& Rowley, D. L. Where is the $\mathrm{F}$ in $\mathrm{MCH}$ ? Father involvement in African American families. Ethnicity \& Disease. 2010;20:S2-S49.

McKinley, D. C., Miller-Rushing, A. J., Ballard, H. L., Bonney, R., Brown, H., Cook-Patton, S. C., et al. Citizen science can improve conservation science, natural resource management, and environmental protection. Biological Conservation 2017; 208:15-28.

Meropol, S. B., Haupt, A. A., Debanne, S. M. Incidence and outcomes of infections caused by multidrug-resistant Enterobacteriaceae in children, 2007-2015. Journal of the Pediatric Infectious Diseases Society 2018; 7: 36-45.

National Aeronautics and Space Administration. (2018). NASA satellite data to the aid of allergy sufferers. Retrieved April 7, 2018 from https://www.nasa.gov/topics/nasalife/pollen.html.

National Council on Aging. (2010). 10 most common chronic conditions in adults 65+. Retrieved April 7, 2018 from http://www. ncoa.org/resources/10-common-chronic-conditions-adults-65.

National Research Council. 2001. New horizons in health: An integrative approach. Washington, DC: The National Academies Press. https://doi.org/10.17226/10002.

Petersen, D. J., \& Weist, E. M. Framing the future by mastering the new public health. Journal of Public Health Management and Practice. 2014;20:371-374.

U.S. Department of Health and Human Services. Office of Adolescent Health. (2018). United States adolescent mental health facts. Retrieved April 7, 2018 from https://www.hhs.gov/ash/oah/facts -and-stats/national-and-state-data-sheets/adolescent-mental-healt h-fact-sheets/united-states/index.html\#footnote-1.

Wise, P. H. Emerging technologies and their impact on disability. The Future of Children. 2012; 22:169-191.

World Health Organization. (2018). WHO calls for urgent action to protect health from climate change-sign the call. Retrieved April 7, 2018 from http://www.who.int/globalchange/global-campaign/ cop21/en/. 